\title{
The Influenced of Compression on Properties of Binderless Compressed Veneer Made from Oil Palm Trunk
}

\author{
Norhafizah Saari", Rokiah Hashim", Othman Sulaiman", Masatoshi Sato* \\ \# School of Industrial Technology, Universiti Sains Malaysia, 11800, Penang, Malaysia. \\ E-mail:fitzhafizah@gmail.com;hrokiah1@gmail.com;osulaiman@gmail.com \\ *Graduate School of Agricultural and Life Sciences, The University of Tokyo, 1138657, Tokyo, Japan. \\ E-mail: amsato@mail.ecc.u-tokyo.ac.jp
}

\begin{abstract}
Binderless compressed veneer panels from oil palm trunk consisted of 5 layers of oil palm trunk veneers were made with 3 different thickness, $7 \mathrm{~mm}, 10 \mathrm{~mm}$ and $15 \mathrm{~mm}$. The panels were pressed at temperature of $180{ }^{\circ} \mathrm{C}$ with pressure $5 \mathrm{MPa}$ at duration time of 20 minutes. The veneers were pressed without using any synthetic adhesive in the manufacturing process. Mechanical and physical properties such as flexural test, thickness swelling and water absorption, density and compression ratio were observed and evaluated based on Japanese Agricultural Standard 2003 (JAS). The findings showed that binderless compressed veneer panels that undergo pressing process with thickness bar $7 \mathrm{~mm}$ showed the highest value of flexural strength compared to other type of panels. Dimensional stability such as thickness swelling and water absorption showed relationship with compression ratio. Based on the results, the compression ratio did influenced the properties of binderless compressed veneer panel made from oil palm trunk.
\end{abstract}

Keywords - oil palm trunk; binderless; compressed veneer; compression ratio.

\section{INTRODUCTION}

Compression is a technique used to increase the density of the final product by decreasing the thickness of the raw material [1], [2]. Compression of wood also known as densification had being practiced since decades ago in particle board industry to produce wear resistant particle board [3]. The technique of densification with varies methods have been reported can improvise the strength in term of physical and mechanical properties of the wood product during its performance [4]. Moreover, this process is believed could smoothen the surface of the final product [5]. Based on previous researches, the compressed wood were produced by using two techniques known as Compreg and the other one is Staypack. Compreg is a wood compression process that involved resin treatment meanwhile Staypack is non-resin treated process [5]. The compression techniques were not just focussing on solid wood only but also applied to other materials such as wood chips and veneers [2],[6],[7].

Recently many researches focused on manufacturing wood based panels without adhesive or resin which is known as binderless board [8], [9], [10]. The ideology of binderless was to produce a product that is environmental friendly product by reducing or not utilize binder in the manufacturing process and at the same time reduce the production cost. This is due to the concern of formaldehyde emission issues [11] [12]. Besides that, the ability of lignocellulosic materials to be bonded together without synthetic adhesive inside the binderless board is called selfbonding activity [13]. However, the research on binderless board studies mostly focused on producing particleboard type panel by using different kind of lignocellulosic materials such as oil palm trunk, rice husk, kenaf, baggase and banana bunch [14], [15], [16].

A few studies had proved that oil palm trunk can be considered as one of a promising lignocellulosic materials to produce a value added wood based panel products such as binderless particleboard, compressed lumber and etc [8], [9], [17]. This is due to its chemical constituent's properties of oil palm trunk itself which is known to be rich with hemicellulose and starch content. The botanical classification of oil palm is Elaeis guineensis Jacq is a native species to west and central of Africa. High production of palm oil as cooking oil had made oil palm become a domestic plant in Malaysia and some other Asian countries. That factor had made this biomass resources easily to be found abundantly in Malaysia as oil palm is one of major plantation in this country. Besides that, oil palm trunk can be categorized as one of a renewable resources because oil palm tree will be replanted after 25-30 years economic life span [18]. The oil palm biomass such as trunk, frond, and 
leaves were estimated had being generated at least 30 million tonnes every year. The objective of this study was to investigate the effect of compression towards the properties of binderless compressed veneer and the possibility of oil palm trunk veneer to be pressed with no consumption of synthetic adhesive.

\section{MATERIALS AND METHODS}

\section{A. Sample preparation}

Oil palm trunks of 25 - 30 years were used to produce veneer in this study. The veneer was made using rotary veneer by peeling process. Then the veneers were cut into dimension $205 \mathrm{~mm} \times 205 \mathrm{~mm} \times 4.5 \mathrm{~mm}$. After that, the veneers were air dried until the moisture content about $10-$ $12 \%$.

\section{B. Board making process}

The dried veneers were arranged perpendicular to each other for 5 layers. The fine particle of oil palm trunk with size pass through $500 \mu \mathrm{m}$ sieve were spread at each layer. Then, the arranged veneers undergo hot pressing process with condition of $180{ }^{\circ} \mathrm{C}$, duration time $20 \mathrm{~min}$ at pressure 5 $\mathrm{MPa}$. The compressed veneer panels were conditioned in a conditioning room for a week. Then the panels will undergo testing to observe its property.

\section{Determination of compression ratio (\%)}

Sample with size $50 \mathrm{~mm}$ x $50 \mathrm{~mm}$ was used for calculation compression. Compression ratio was calculated based on the equation:

$$
\text { Compression ratio }=\left[\left(\mathrm{T}_{1}-\mathrm{T}_{0}\right) / \mathrm{T}_{1}\right] \times 100
$$

Where, $\mathrm{T}_{1}$ : thickness before compression

$$
\mathrm{T}_{0} \text { : thickness after compression }
$$

\section{Thickness swelling and water absorption}

The shrinkage and swelling study includes thickness swelling and water absorption were carried out based on JAS of plywood-2003 [19]. The standard was slightly modified to accommodate the panel size and then being immersed in the hot water with temperature of $60 \pm 3{ }^{\circ} \mathrm{C}$ for duration $3 \mathrm{hr}$.

\section{E. Modulus of rupture}

The Modulus of rupture of the compressed veneer was tested by using Instron machine. This testing was evaluated based on JAS of plywood-2003 [19] with slightly modified to suit the size of the compressed veneer. The defection was measured and calculated based on Bending Young's Modulus formula.

Bending Young's Modulus ( $\mathrm{MPa}$ or $\left.\mathrm{N} / \mathrm{mm}^{2}\right)=\Delta \mathrm{P} \ell^{3} / 4 \mathrm{bh}^{3} \Delta \mathrm{y}$

\section{F. Scanning electron microscopy (SEM) study}

Scanning electron microscopy (SEM) was employed to compressed veneer panels in order to characterize the morphology which related to the effect of compression towards raw materials and the bonding quality. The micrograph was viewed using machine Scanning Electron Microscope LEO Supra 50 Vp, Field Emission SEM.

\section{RESULTS AND DISCUSSION}

The data on density and compression ratio of binderless compressed veneer from oil palm trunk with different thickness were presented in Table 1 . The density values showed the compactness of the panel together with the percentage of compression ratio of 5 layers of veneers which had being compressed into 3 different target thicknesses.

TABLE I

THE VALUES OF DENSITY AND COMPRESSION RATIO OF VENEER OF BINDERLESS COMPRESSED VENEER PANELS FROM OIL PALM TRUNK FOR DIFFERENT THICKNESS

\begin{tabular}{|c|c|c|}
\hline $\begin{array}{c}\text { Thickness } \\
(\mathbf{m m})\end{array}$ & Density $\left(\mathbf{g} / \mathbf{c m}^{\mathbf{3}}\right)$ & Compression ratio (\%) \\
\hline 7 & $1.02(0.06)$ & $68.89(0.57)$ \\
10 & $0.65(0.07)$ & $55.56(0.64)$ \\
15 & $0.57(0.05)$ & $33.33(0.59)$ \\
\hline \multicolumn{2}{|c|}{} \\
\hline
\end{tabular}

Table 1 showed the density and compression ratio values of binderless compressed veneer from oil palm trunk. Based on the data above, the density values of the panels was effected by the degree of compression that was carried out during pressing process. The total layers used in this study was 5 layers of veneers for each panel that were arranged perpendicular to each other. The different was the thickness spencer used which were $7 \mathrm{~mm}, 10 \mathrm{~mm}$ and $15 \mathrm{~mm}$. Binderless compressed veneer panel with thickness $7 \mathrm{~mm}$ had the highest density values followed by sample with thickness $10 \mathrm{~mm}$ and $15 \mathrm{~mm}$. This factor is related to the compression degree where the panel with thickness $7 \mathrm{~mm}$ had being highly compressed and compacted which reduced the void inside the panel. Higher compression will cause higher in density which influenced the strength and compactness of the binderless compressed veneer [20]. The degree of compression of the panels with thickness $10 \mathrm{~mm}$ and $15 \mathrm{~mm}$ not so high.

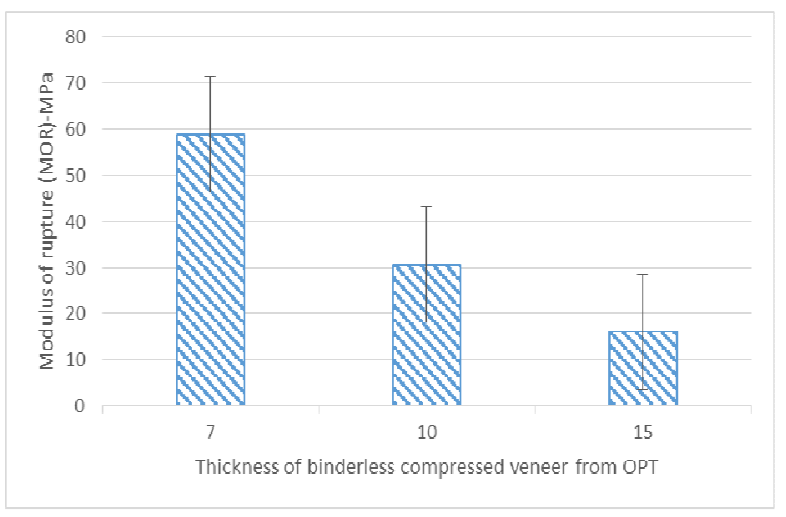

Fig. 1: Relationship thickness of binderless compressed veneer panel with MOR

Fig. 1 showed the effect of compression ratio towards the modulus of rupture (MOR) of binderless compressed veneer panel from oil palm trunk. The highest values found in panel with thickness $7 \mathrm{~mm}, 58.9 \mathrm{MPa}$ followed by panel with thickness $10 \mathrm{~mm}$ and $15 \mathrm{~mm} 30.8 \mathrm{MPa}$ and 16.2 $\mathrm{MPa}$ respectively. This findings were correlated with compression degree and density values. High in density will produce high 
modulus of rupture values. Compressed veneer with thickness $7 \mathrm{~mm}$ and $10 \mathrm{~mm}$ had met the standard based on Japanese Agricultural Standard 2003 (JAS) [19]. The compression happened during hot pressing process somehow had degraded hemicellulose which weaken the cell wall and caused the parenchyma cells inside the panel to be completely compressed. Moreover, the reduction of total volume which related to the increment of density of the binderless compressed veneer panel had caused the strength of the board increase. The panel with thickness $7 \mathrm{~mm}$ showed good bonding quality created during compression process which resulted in high strength even though no adhesive being added. Binderless compressed veneer panel with thickness $15 \mathrm{~mm}$ showed the lowest reading because the veneers not completely pressed.

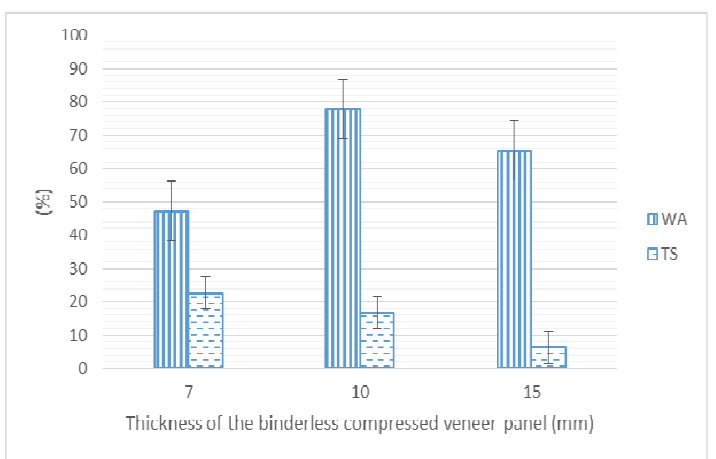

Fig. 2: Relationship thickness of binderless compressed veneer panel with water absorption and water absorption

Shrinkage and swelling of the compressed veneer panels from oil palm trunk can be observed based on Fig 2. The values of water absorption and thickness swelling showed contrary pattern. Water absorption values increased from panel with thickness $7 \mathrm{~mm}$ to $10 \mathrm{~mm}$ and drop a little bit for panel with thickness $15 \mathrm{~mm}$. however the values of thickness swelling decreased as the thickness were increased. This findings somehow related to density values. The panel with thickness $7 \mathrm{~mm}$ showed the lowest WA compared to the other panels due to compactness phenomenon and degree of compression happened inside the panel where most of the fibres completely pressed caused no void inside the panel. Thus, water intake become less. The compressed veneer panel with thickness $10 \mathrm{~mm}$ showed the highest WA because the water intake was the highest among the panels as the veneers not completely pressed and still got void inside the panel. Therefore too much water intake will cause the panel easily peel of layers by layers of veneer. However, TS showed opposite result.

Fig 3 showed the interphase morphology of binderless compressed veneer from oil palm trunk with thickness $7 \mathrm{~mm}$ thickness. Based on the figure above, the fibres and cell walls can be seen completely compressed during the pressing process [11]. Besides that, the vascular bundles also discovered to be compressed. The vascular bundles is the main element in the oil palm trunk which responsible to give mechanical strength to the binderless compressed veneer panel. The pressed parenchyma cells also being observed in the Fig 3. The compactness and pressed fibres had contributed to the better dimensional stability in term of water absorption [21]. Moreover, mechanical interlocking between fibres happened when the fibres and cells inside the panel being completely pressed together [11].
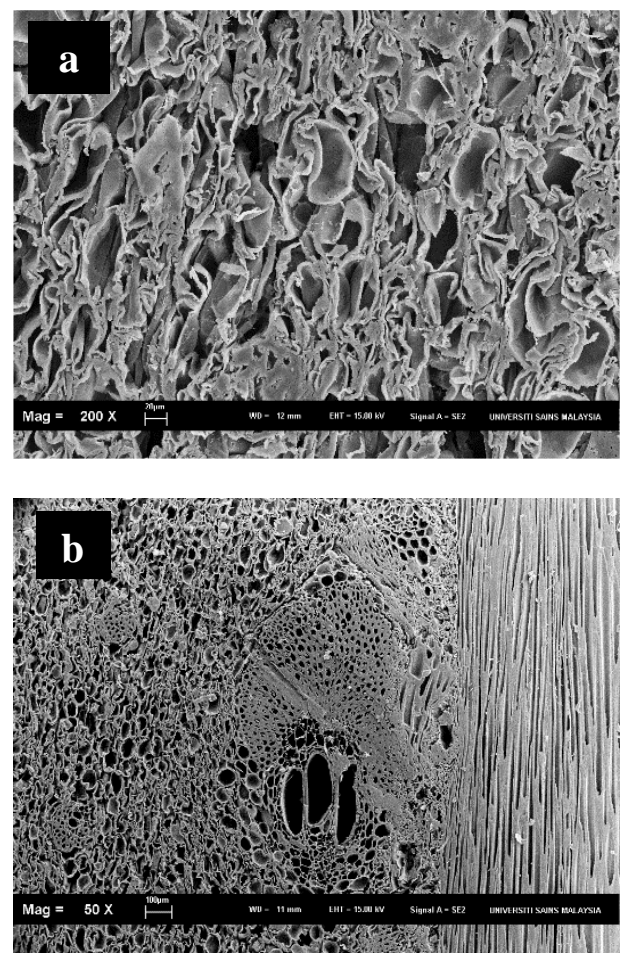

Fig. 3 (a) \& (b): Scanning electron microscopy micrographs of binderless compressed veneer panel of oil palm trunk with thickness $7 \mathrm{~mm}$

\section{CONCLUSIONS}

The findings showed that high compression and compactness will caused the binderless compressed veneer panel made from oil palm trunk increase in modulus of rupture and its density. Besides that, the 5 layers of oil palm trunk veneer can be bonded together with hot pressing method even though no additional synthetic being utilized. This binderless compressed veneer panel with $7 \mathrm{~mm}$ thickness showed good modulus of rupture and improvement in dimensional stability properties in term of water absorption. Thus proved that compression did influenced some properties of binderless compressed veneer from oil palm trunk. Further study and modification are needed because some properties such as thickness swelling and water absorption still did not meet the standard. However oil palm trunk veneer have high potential to be used as raw material for binderless compressed veneer product.

\section{ACKNOWLEDGMENT}

The authors would like to acknowledge Ministry of Higher Education (MOHE) for the MyPhd scholarship to Norhafizah Saari and Universiti Sains Malaysia for Research University Grant 1001/PTEKIND/811255.

\section{REFERENCES}

[1] Bekhta, P.A., and Marutzky, R. Reduction of glue consumption in the plywood production by using previously compressed veneer, Holz Roh Werkst, 200765 (1), 87-8

[2] Adachi, K., Inoue, M., Kannyama, K., Rowell, R.M., and Kawai, S. Water removal of wet veneer by roller pressing. J. Wood Sci., 2004, 50, 479-83 
[3] Wingate-Hill, R. A review of processes which involve compressing wood perpendicular to the grain. Autralia Forest Research, 1983, 13:151-164

[4] Fang, C-H., Mariotti, N., Cloutier, A., Koubaa, A., and Blanchet, P. Densification of wood veneers by compression combined with heat and steam, European Journal Wood Products, 2012, 70:155-163

[5] Candan, Z., Hiziroglu, S., GMcDonald, G. Surface quality of thermally compressed Douglas fir veneer, Material \& Design, 2010, 31:3574-3577

[6] Bekhta, P., Hiziroglu, S., and Shepelyuk, O. Properties of plywood manufactured from compressed veneer as building material, Mater Design, 2009, 30, 947-953

[7] Unsal, O., Kartal, S.N., Cendan, Z., Avango, R.A., Clausen, C.A. and Green, F. Decay and termite resistance, water absorption and swelling of thermally compressed wood panels, Int. Biodeter. Biodegr, 2009, 63, 548-552

[8] Hashim, R., Wan Nadhari, W.N.A., Sulaiman, O., Kawamura, F., Hiziroglu, S., Sato, M., Tay, G.S., Tanaka, R. Characterization of raw materials and manufactured binderless particleboard from oil palm biomass, Mater Design, 2011, 32(1), 246-254

[9] Hashim, R., Said, N., Lamaming, J., Baskaran, M., Sulaiman, O., Sato, M., Hiziroglu, S., Sugimoto, T. Influence of press temperature on the properties of binderless particleboard made from oil palm trunk, Mater Design, 2011, 32(5), 2520-2525

[10] Widyorini, R., Xu, J., Umemura, K., Kawai, S. Manufacture and properties of binderless particleboard from baggase I: effects of raw material type, storage methods, and manufacturing process, $J$. Wood Sci., 2005, 51, 648-654

[11] Hashim, R., Sarmin, S.N., Sulaiman, O., Yusuf, L.H.M. Effect of cold setting adhesives on properties of laminated veneer lumber from oil palm trunk in comparison with rubberwood. Eur $J$ Wood Prod, $2010,69,53-61$
[12] Hashim, R., Hamid, S.H.A., Sulaiman, O., Ismail, N., Ibrahim, M.H., Jais, H. Extractable formaldehyde from waste medium density fibreboard, J Trop Forest Sci., 2009, 21, 25-33

[13] Ando, M., and Sato. M. Evaluation of the self-bonding ability of sugi and application of sugi powder as a binder for plywood, $J$ Wood Sci. 2010, 56, 194-200

[14] Boon, J.G., Hashim, R., Sulaiman, O., Hiziroglu, S., Sugimoto, T., Sato, M. Influence of processing parameters on some properties of oil palm trunk binderless particleboard, Eur. J. Wood Prod, 2013, 71, 583-89

[15] Xu, J., Sugawara, R., Widyorini, R., Han, G., Kawai. Manufacture and properties of low-density binderless particleboard from kenaf core, J Wood Sci., 2004, 50: 62-67

[16] Velasquez, J.A., Ferrando, F., Salvado, J. Binderless fibreboard from steam exploded Miscanthus sinensis: The effect of a grinding process, Holz als Roh-und Werkstoff, 2002, 60, 297-302

[17] Salim, N., Hashim, R., Sulaiman, O., Nordin, N.A., Ibrahim, M., Md Akil, H., Sato, M., Sugimoto, T., and Hiziroglu, S. Effect of steaming on some properties of compressed oil palm trunk lumber, BioResources, 2013, 8(2), 2310-2324

[18] Ahmad, Z., Saman, H, M., and Tahir, P, M. Oilp palm trunk fiber as a biowaste resource for concrete reinforcement. International Journal of Machanical and Materials Engineering, 2010, 5(2): 199-207

[19] Japanese Agricultural Standard (2003) JAS for plywood. Japanese Agricultural Standards Association, Tokyo

[20] Welzbacher, C.R., Wehsener, J., Rapp, A.O., and Haller, P. Thermomechanical densification combined with thermal modification of Norway Spruce (Piciea a bies Karst) in industrial scale- Dimensional stability and durability aspects, Holz Als RohUnd Werkstoff, 2008, 66; 39-49

[21] Lim, S.C, Gan, K.S. Characteristics and utilization of oil palm stem. Timber technology bulletin no. 35 Malaysia, 2005, Forest Research Institute Malaysia. 